\title{
Personality Traits and Performance of Immigrant-Owned Small Businesses
}

\author{
Olawale Fatoki
}

\author{
Department of Business Management, University of Limpopo, Private Bag X1314, Sovenga, 0727, South \\ Africa
}

\begin{abstract}
Motivation: Immigrant entrepreneurs contribute to employment and the sustainable growth of host countries and both native and immigrant-owned enterprises should be included in the growth and employment strategy of a country. However, immigrant-owned small businesses face many challenges which impact on their performance and survival. The personality traits of immigrant entrepreneurs can influence the strategy adopted and implemented to improve business performance.
\end{abstract}

Novelty: The aim of the study is to examine the effect of owners' personality traits on the performance of immigrantowned small businesses using the Five-Factor model. Empirical studies that specifically focus on the effect of personality traits on the performance of immigrant-owned small businesses are scarce.

\begin{abstract}
Methodology and Methods: The cross sectional survey method was used for data collection in a quantitative study. Data was collected from one hundred and ninety-six immigrant entrepreneurs and the participants in the survey were conveniently sampled. The participants of this study were in the retail and service businesses and were immigrants with legal residency in South Africa.

Data and Empirical Analysis: The Partial Least Square Structural Equation Modelling (PLS SEM) was used for analysis. The results indicated significant positive relationships between three personality traits (openness to experience, conscientiousness, extraversion) and the performance of immigrant-owned small businesses. The influence of agreeableness is insignificant while the effect of neuroticism is significantly negative.

Policy Considerations: The findings this study can help individuals, businesses and government agencies that support small businesses to understand the personality traits that can help to improve the performance of immigrant-owned businesses. The design of training programme to improve the performance of immigrant-owned businesses should include how to enhance the personality traits of immigrant entrepreneurs especially openness to experience, conscientiousness and extraversion. The employment strategy of immigrant-owned small businesses should focus on individuals with these performance-enhancing personality traits.
\end{abstract}

Keywords: Personality traits, five-factor theory, small and medium enterprises, immigrants, performance.

\section{INTRODUCTION}

Small and medium and micro enterprises (SMMEs) play an important role in the economies of countries around the world. SMMEs generate employment and value added and contribute to the gross domestic product. In South Africa, the SMME sector accounts for $98.5 \%$ of all firms and contribute $28 \%$ of all jobs (Small Business Institute, 2018). The small business sector in many countries include both native and immigrantowned enterprises. A native entrepreneur is a person that was born in a country and starts business in that country. An immigrant entrepreneur is an individual that was born in another country, relocates and starts a business in the host country (Osorio et al., 2015; Omisakin, 2017). Immigrant entrepreneurs contribute to employment and the sustainable growth of host countries and both native and immigrant-owned enterprises should be included in the growth and

Address correspondence to this author at the Department of Business Management, University of Limpopo, Private Bag X1314, Sovenga, 0727, South Africa; Tel: +27 015268 2646; E-mail: olawale.fatoki@ul.ac.za

JEL Classification: L26. employment strategy of a country (Kalitanyi \& Visser, 2010; Tengeh \& Nkem, 2017). Prior research is inconclusive about the performance of immigrant and native-owned businesses. Some studies find that native-owned businesses perform better than immigrant-owned businesses while other studies contend the opposite. Despite these inconclusive findings, it is certain that many immigrant-owned small businesses, just like those that are owned by natives, face many challenges which impact on their performance and survival. The challenges encountered by immigrant-owned small businesses include language and cultural barriers, inaccessibility to external finance and a highly competitive business environment (Vinogradov \& Isaksen, 2007; Tella, 2015).

Personality traits contribute to entrepreneurial prowess and the personal characteristics of the owner can influence the strategies adopted and implemented by small businesses (Bajwa et al., 2017; Mhlanga, 2019). Personality traits belong to the psychological approach to entrepreneurship that began in the 1960s with McClelland linking the need for achievement to 
entrepreneurial tendencies. Notwithstanding the vast number of psychological studies, researchers continue to study a collection of personality traits that characterise entrepreneurs (Owens et al., 2013). Personality traits describe an individual's characteristics patterns of feelings, thought and behaviour that are consistent and stable over time. Trait psychology is based on the assumption that people are different from one another on the basis of a set of basic trait dimensions that are stable over time and across situations. Many theories such as the Eysenck's Personality Theory and HEXACO have been used to examine personality traits, however, the FiveFactor theory or the Big Five which describes the important traits that function as the building blocks of personality is the most widely used model in entrepreneurship research. The identification of owners' personality traits can help to improve the performance of small businesses (Goldberg, 1990; Hachana et al., 2018; Mhlanga, 2019).

The aim of the study is to examine the effect of owners' personality traits on the performance of immigrant-owned small businesses using the FiveFactor model. The study will be significant to academia, individuals and businesses in the following ways. First, there is little agreement about the influence of personality traits as predictors of business performance. Previous empirical studies have reached different conclusions about the effects of the five basic dimensions of the five-factor personality traits as predictors of entrepreneurial performance (Leutner et al., 2014). Second, empirical studies that specifically focus on the effect of personality traits on the performance of immigrant-owned small businesses are scarce. Immigrant-owned businesses suffer from a high failure rate and the findings of this study will help immigrant entrepreneurs to understand the personality traits that can help to enhance business performance. This can lead to proactive measures by immigrant entrepreneurs to develop such performance-enhancing traits or employ individuals with such traits (Kerr et al., 2017; Omar et al., 2017). The paper is structured as follows. Section two reviews the literature and develops the hypotheses. Section three depicts the research methodology while section four presents the results. The discussion and conclusion are provided in sections five and six.

\section{LITERATURE REVIEW}

\subsection{Definition of Small, Medium and Micro Enterprises in South Africa}

The National Small Business Act of 1996, as revised in 2003, defines a small business as "a separate distinct entity including cooperative enterprises and non-governmental organisations managed by one owner or more, including branches or subsidiaries if any is predominately carried out in any sector or subsector of the economy mentioned in the schedule of size standards". There are three enterprise classes for SMMEs in South Africa. These are micro, small and medium. The quantitative definition focuses on the number of employees and total annual turnover (Government Gazette, 2019). Table 1 depicts the definition of SMMEs in the retail and service sectors in South Africa.

The number of employees is one of the indicators that is used to classify SMMEs in South Africa. Quantitatively, a micro enterprise in the retail and service sectors will have between 0 and 10 employees, small enterprises between 11 and 50 employees, and medium enterprises between 51 and 250 employees (Government Gazette, 2019).

\subsection{Immigrant Entrepreneurship}

Immigrant entrepreneurship can be described as a situation where an immigrant ventures into business creation in a host country (Tella, 2015). Theoretically, immigrant entrepreneurship can be linked to the Theory of Middleman Minorities, the Disadvantage theory, the Ethnic enclave theory, the Ecological theory, the Cultural theory, the Opportunity structure theory and the Interactive theory. The Theory of Middleman Minorities by Bonacich (1973) explains that immigrant entrepreneurs serve as an intermediary between the

Table 1: Definition of Small and Medium Enterprises in South Africa

\begin{tabular}{|c|c|c|}
\hline Size or class of enterprise & Total full-time paid employees & Total annual turnover \\
\hline Micro & $0-10$ & Less or equal to $\mathrm{R} 7.5 \mathrm{~m}$ \\
\hline Small & $11-50$ & Less or equal to $\mathrm{R} 25 \mathrm{~m}$ \\
\hline Medium & $51-250$ & Less or equal to $\mathrm{R} 80 \mathrm{~m}$ \\
\hline
\end{tabular}

Adapted from Government Gazette (2019). 
majority group and other ethnic groups. The Disadvantage theory by Light (1979) argues that immigrants create their own businesses because of they are disadvantaged in the labour markets of host countries. The Ethnic enclave theory by Wilson \& Portes (1980) stipulates that there is a spatial concentration of businesses owned by immigrants from the same country of origin. The Cultural theory by Masurel et al. (2004) contends that immigrant have some culturally determined features such as hard work, austere living, ethnic social network and orientation towards self-employment that tend to encourage entrepreneurship. The Opportunity structure theory by Evans (1989) suggests that the host country offers opportunities that can be tapped by immigrant entrepreneurs. These include the preferences of consumers in the ethnic group and the skills and resources of co-ethnics. The interactive model by Waldinger et al. (1990) contends that immigrant entrepreneurship cannot be associated with a single feature but to an intricate interaction between opportunity structure and group resources.

\subsection{The Five-Factor Theory of Personality}

Personality traits describe an individual's characteristics patterns of feelings, thought and behaviour that are consistent and stable over a period of time. According to Antoncic et al. (2015), the initial work on the taxonomy of personality traits can be linked to Allport \& Odbert (1936) which acknowledged about 4,500 dictionary words that could be used to explain personality traits. Norman (1967) identified five basic factors and Goldberg $(1981,1990)$ labeled the factors the Five-factor or the Big five. The Five-factor theory of personality depicts a hierarchical organisation of personality traits in terms of five basic dimensions: Extraversion, Agreeableness, Conscientiousness, Neuroticism, and Openness to Experience (Goldberg, 1990; McCrae \& John, 1992). The five-factor theory is a multidimensional model and has been the dominant model of personality traits since the 1980s (Kerr et al., 2017). Agreeableness explains the tendency of an individual to be warm compassionate, generous, cooperative and in social harmony. Openness to experience refers to an individual's appreciation of diverse and unusual experiences. Individuals with high levels of openness to experience tend to be more broad-minded, intelligent, creative, artistically sensitive and curious. Conscientiousness focuses on a high level of responsibility, organisation, self-discipline, eagerness to follow rules and future-orientation by an individual. Extraversion explains the tendency of an individual to be social, assertive, energetic, outgoing and helpful to other people. Neuroticism describes the extent to which an individual is aggressive, anxious, angry and emotionally unstable (McCrae \& John, 1992). The Big five model of personality traits has been widely used to predict individual actions in the area of entrepreneurial performance (Antoncic et al., 2015; Mhlanga, 2019).

\subsubsection{Agreeableness and Business Performance}

The literature is not conclusive about the effect of agreeableness on entrepreneurial performance. Antoncic et al. (2015) remark that the agreeableness factor consists of traits that can be associated with entrepreneurship in both directions. Agreeableness can make entrepreneurs to be cooperative, helpful and friendly, but on the other hand can make them to be combative, demanding and domineering. Therefore, there is the potential ambiguity of agreeableness because of the duality of its meaning. The study by Howard and Howard (1995) find that entrepreneurs score average on agreeableness and so there is no strong relationship between agreeableness and entrepreneurship. Hachana et al. (2018) and Mhlanga (2019) find an insignificant relationship between agreeableness and entrepreneurial performance. The findings of the two studies suggest that being softhearted and tolerant may negatively affect the ability to take difficult decisions necessary to ensure business success. Zhao and Seibert (2006) remark that a high level of agreeableness may constrain the willingness of an entrepreneur to drive hard bargains, protect selfinterest and influence other people for one's own advantage. Another stream of research reports a significant positive relationship between agreeableness and entrepreneurial performance. Agreeable entrepreneurs are cooperative, caring, gentle and empathetic and this can help in maintaining coordination or cooperation with employees in a business (Cantner et al.,2011; Jawabri, 2019). A high level of agreeableness can lead to a positive relationship between entrepreneurs and employees, customers and other stakeholders. Therefore, agreeableness can help a business to increase turnover and raise funds from external financiers with a positive impact on performance (Antoncic et al., 2015; Kerr et al., 2018). Consequently, it is hypothesised that:

Hypothesis 1: There is a significant positive relationship between entrepreneurs high in agreeableness and business performance. 


\subsubsection{Openness to Experience and Business Performance}

Antoncic et al. (2015) point out that entrepreneurial success is linked to opportunity alertness, creativity and innovation and eentrepreneurs dislike routine repetitive work. Kerr et al. (2018) remark that openness to experience includes the ability of an entrepreneur to negotiate and manage changing business environment leading to business success. Openness to experience helps the entrepreneur to develop creative and imaginative solutions to business problems and an effective environment for teamwork to flourish (Shane, 2010; Cantner et al., 2011). Hachana et al. (2013) and Mhlanga (2019) provide empirical evidence of a positive relationship between openness to experience and business performance. Entrepreneurs with high levels of openness to experience are imaginative, creative, flexible, intellectually curious, adaptable to change and have a high level of learning orientation. Consequently, it is hypothesised that:

Hypothesis 2: There is a significant positive relationship between entrepreneurs high in openness to experience and business performance.

\subsubsection{Conscientiousness and Business Performance}

The findings of empirical studies about the relationship between conscientiousness and entrepreneurial performance are inconclusive. Conscientiousness may lead to workaholic behaviour, compulsive neatness and annoying fastidiousness. Conscientious entrepreneurs tend to focus on task accomplishment and lack creativity with a negative effect on performance (Costa \& McCrae, 1992; Cantner et al., 2011). Another stream of research (Zhao \& Seibert, 2006; Zhao et al., 2010, Hachana et al., 2013, Mhlanga, 2019; Jawabri, 2019) concludes that conscientiousness has a positive association with entrepreneurial performance. Entrepreneurs with high levels of conscientiousness tend to score high on the need for achievement, the desire to take personal responsibility for their decisions, willingness to take decisions, risk-taking and goal orientation (Antoncic et al., 2015; Kerr et al., 2018). It is hypothesised that:

Hypothesis 3: There is a significant positive relationship between entrepreneurs high in conscientiousness and business performance.

\subsubsection{Extraversion and Business Performance}

Hachana et al. (2018) remark that extraverted entrepreneurs are able to develop solid networks which help to maintain strong partnerships with customers, suppliers and providers of capital. Zhao and Seibert (2006) and Cantner et al. (2011) point out that extraverts use their sociability to enhance employee commitment and develop extensive social interactions. Zhao et al. (2010), Hachana et al. (2018) and Jawabri (2019) find a significant positive relationship between extraversion and entrepreneurial performance. According to Antoncic et al. (2015), extraverts tend to be optimistic, active, energetic, assertive and dominant and extraversion may enable the achievement of organisational goals. Consequently, it is hypothesised that:

Hypothesis 4: There is a significant positive relationship between entrepreneurs high in extraversion and business performance.

\subsubsection{Neuroticism and Business Performance}

Antoncic et al. (2015) point out that emotional stability is an important trait for personal success and this suggests the possibility of a negative association between the neuroticism (the reverse of emotional stability) and entrepreneurship. The traits of individuals with high levels of neuroticism include anxiety, depression, hostility and vulnerability and this may negatively affect relationships with customers, suppliers and providers of capital (Hachana et al., 2018). Singh and De Noble (2003) provide evidence of a negative relationships between neuroticism and selfemployment measured by intent and perceived ability. Neuroticism is likely to reduce the ability of an individual to build social capital and the propensity to take risks (Baluku et al., 2016). Empirical studies by Zhao et al. (2010), Hachana et al. (2018) and Mhlanga (2019) find a significant negative relationship between neuroticism and entrepreneurial performance. Neuroticism negatively affects the willingness of an entrepreneur to take risk, maintain relationships with stakeholders and persevere in business. Neurotic individuals are emotionally unstable and this may adversely affect entrepreneurial behaviour and performance. It is hypothesised that:

Hypothesis 5: There is a significant negative relationship between entrepreneurs high in neuroticism and business performance.

The conceptual model of the study is depicted by Figure 1.

\section{RESEARCH METHODOLOGY}

The study adopted the quantitative research approach and the self-administered questionnaire 


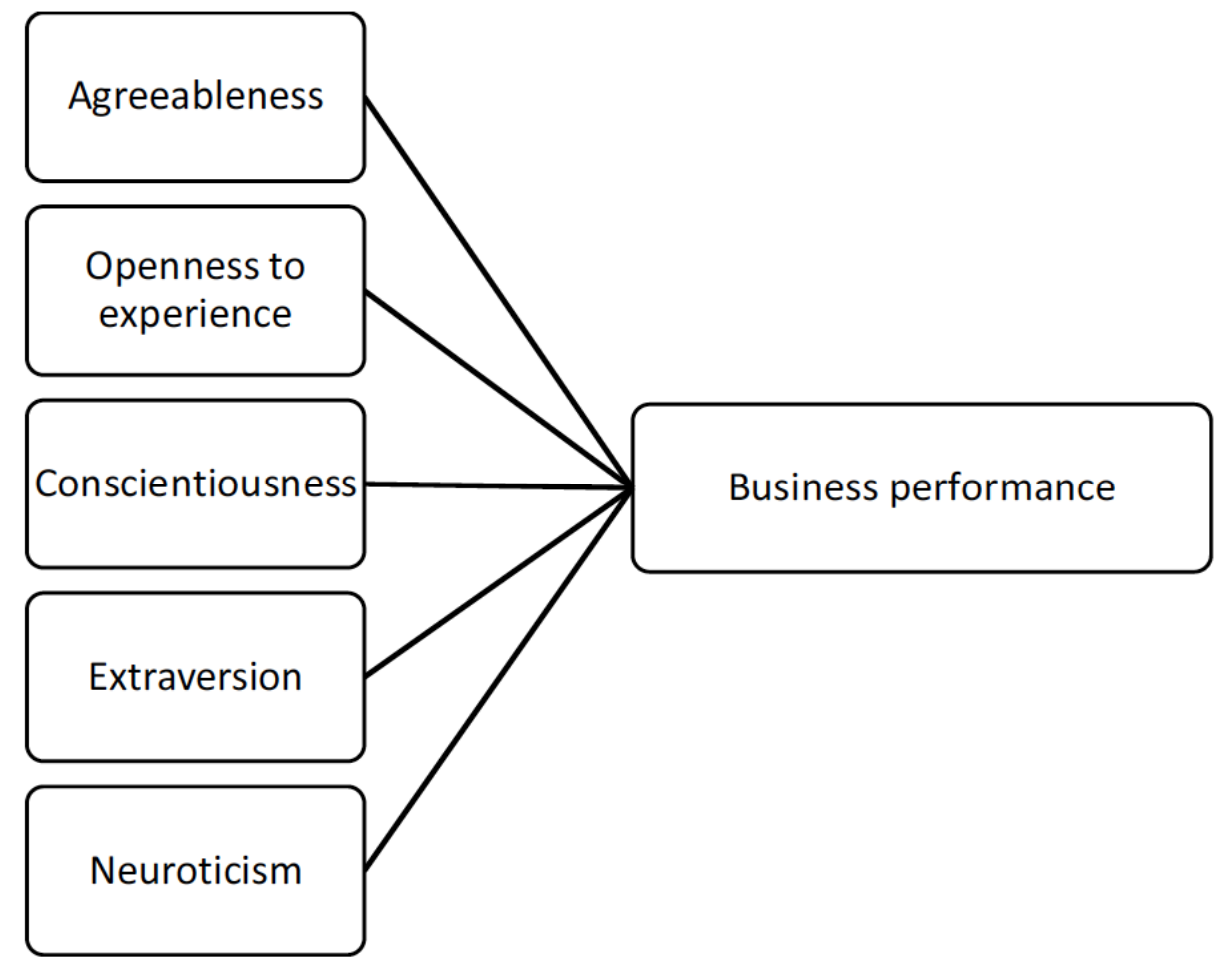

Figure 1: conceptual model.

method was used to collect data from survey participants. The cross-sectional survey approach was adopted and data collection took place between May and November 2019 in the Central Business Districts of Johannesburg and Pretoria in the Gauteng province and Polokwane in the Limpopo Province of South Africa. These areas were used for the survey because they contain a large number of immigrant-owned small businesses. There is no available population frame of immigrant-owned small businesses in the study area and the participants in the survey were conveniently sampled. The participants of this study were in the retail and service businesses and were immigrants with legal residency in South Africa. Three field agents assisted in the data collection process and a pilot study was conducted on the survey instrument with thirty immigrant small business owners. Minor adjustments were made to the questionnaire based on the feedback from the pilot study. The questionnaire was divided into three sections (1) biographical details (2) personality traits and (3) business performance. The cover page of the questionnaire contained information about the aim of the study and voluntary and anonymous participation. Descriptive analysis and PLS SEM were used for analysis. Measures: Scales with acceptable psychometric properties were adapted for all the constructs from previous studies on personality traits and business performance. The questionnaire items are depicted in Appendix 1.

\section{RESULTS}

\subsection{Biographical Details}

500 questionnaires were distributed to immigrant entrepreneurs and 196 questionnaires were completed and returned. The response rate was $39.6 \%$. The results of the Kolmogorov-Smirnov assured the normality of the data. T-test and Anova results did not indicate any significant differences in the results on the basis of demographic variables.

Table 2 depicts the biographical details. The results indicate that the majority of the participants in the survey are male, with post matric qualifications, have been in business for between six and ten years and in the $31-40$ age bracket and can be classified as micro enterprises.

\subsection{Descriptive Analysis}

Table 1 shows the summary of the descriptive statistics. The highest score that an individual can score in a personality trait is a score of 5.0. the mean score of agreeableness is $3.15(S D=1.09)$. The mean scores for conscientiousness is $4.22(S D=1.16)$, extraversion $3.60(S D=1.06)$, openness to experience $4.05(\mathrm{SD}=1.02)$ and neuroticism $2.72 \quad(\mathrm{SD}=1.06)$. Business performance has a mean score of 3.48 $(S D=1.02)$. 
Table 2: Biographical Information of the Respondents

\begin{tabular}{|c|c|}
\hline Biographical characteristics & $\begin{array}{l}\text { Frequency } \\
(\mathrm{N}=196)\end{array}$ \\
\hline \multicolumn{2}{|c|}{ Educational qualification of owner/manager } \\
\hline Matric equivalent or below & 82 \\
\hline Post-Matric qualifications & 114 \\
\hline \multicolumn{2}{|l|}{ Gender } \\
\hline Female & 72 \\
\hline Male & 124 \\
\hline \multicolumn{2}{|l|}{ Age of the owner (year) } \\
\hline Less than 20 & 2 \\
\hline $20-30$ & 68 \\
\hline $31-40$ & 85 \\
\hline $41-50$ & 21 \\
\hline Above 50 & 8 \\
\hline \multicolumn{2}{|l|}{ Age of the firm (year) } \\
\hline Less than one & 14 \\
\hline $1-5$ & 71 \\
\hline $6-10$ & 109 \\
\hline Above ten years & 2 \\
\hline \multicolumn{2}{|l|}{ Number of employees } \\
\hline No employees & 56 \\
\hline 1-4 employees & 133 \\
\hline 5-9 employees & 7 \\
\hline 10-49 employees & 0 \\
\hline 50-99 employees & 0 \\
\hline
\end{tabular}

Table 3: Descriptive Statistics

\begin{tabular}{|c|c|c|}
\hline Construct & Mean & Standard deviation \\
\hline \hline Agreeableness & 3.15 & 1.09 \\
\hline Conscientiousness & 4.22 & 1.16 \\
\hline Extraversion & 3.60 & 1.06 \\
\hline Openness to experience & 4.05 & 1.02 \\
\hline Neuroticism & 2.72 & 1.06 \\
\hline Performance & 3.48 & 1.02 \\
\hline
\end{tabular}

\subsection{Structural Equation Modelling}

The Partial Least Square Structural Equation modelling (The PLS SEM) was used to examine the research model using the software package Smart PLS 3.0. PLS SEM is a powerful and widely used method to examine latent variables. Chin (2010) remarks that PLS has the ability to process complicated models and does not require distributional assumptions for the sample. The PLS SEM comprises of two sub-models and these are the measurement and structural models (Hair et al., 2019]. First the measurement model was tested for reliability and validity after which the structural model was examined to test the hypotheses of the study.

\subsubsection{Measurement Model}

The study followed the criteria of Hair et al. (2019) for the evaluation of the measurement model. These include the examination of factor loadings $(>0.708)$, composite reliability (between 0.790 and 0.900 ), Cronbach's alpha $(>0.700$ ) and the AVE (minimum 0.500 ). Also, the square roots of the AVEs should be greater than the correlations amongst variables. The results as indicated by Table 3 showed that all the items used to measure the constructs of the study have loading above 0.708 and are retained. The composite reliability values for the constructs ranged between 0.813 and 0.873 . In addition, the Cronbach's alpha coefficients for all the construct range between 0.724 and 0.812 indicating a satisfactory internal consistency of measures. This implies an acceptable level of construct validity. The AVEs ranged between 0.590 and 0.711 suggesting a good convergent validity of the scales. The Fornell \& Larcker criteria was used to assess discriminant validity. The results as depicted in Table 5 showed that the square roots of AVEs are depicted on the diagonals are greater than the corresponding correlation coefficients within the constructs. It can be concluded that the measurement model is satisfactory.

\section{$\underline{\text { Structural Model Assessment }}$}

Following the suggestions by Hair et al. (2019), the likelihood of common method bias (CMB) was examined. The VIFs for the constructs of the study were lower than 3.3 suggesting that the model is not constrained by CMB (Henseler et al., 2015). The $R^{2}$ obtained by the study is 0.591 indicates a high level of predictive accuracy of the model. The value of the goodness of fit (GIF) is 0.623 suggesting that the empirical data satisfactorily fits the model and has a good predictive power in comparison to baseline values. The predictive relevance of the model $\left(Q^{2}\right)$ using the cross validated communality is 0.59 which is indicative of a predictive model. The effect size, $f^{2}$, ranged from 0.01 to 0.14 indicating small to medium effect sizes of different endogenous constructs on the exogenous construct. The standardised root mean square residual (SRMR) of 0.03 is indicative of a good 
Table 4: The Measurement Model

\begin{tabular}{|c|c|c|c|c|c|}
\hline Construct & Measurement items & Item loading & Cronbach's alpha & Composite reliability & AVE \\
\hline \multirow{3}{*}{ Agreeableness (AGR) } & AGR1 & 0.869 & \multirow{3}{*}{0.812} & \multirow{3}{*}{0.866} & \multirow{3}{*}{0.683} \\
\hline & AGR2 & 0.831 & & & \\
\hline & AGR3 & 0.777 & & & \\
\hline \multirow{3}{*}{ Extraversion (EXT) } & EXT1 & 0.837 & \multirow{3}{*}{0.774} & \multirow{3}{*}{0.843} & \multirow{3}{*}{0.642} \\
\hline & EXT2 & 0.748 & & & \\
\hline & EXT3 & 0.816 & & & \\
\hline \multirow{3}{*}{ Conscientiousness (CON) } & CON1 & 0.877 & \multirow{3}{*}{0.762} & \multirow{3}{*}{0.862} & \multirow{3}{*}{0.676} \\
\hline & CON2 & 0.786 & & & \\
\hline & CON3 & 0.801 & & & \\
\hline \multirow{3}{*}{ Openness to experience (OPE) } & OPE1 & 0.882 & \multirow{3}{*}{0.803} & \multirow{3}{*}{0.873} & \multirow{3}{*}{0.697} \\
\hline & OPE2 & 0.838 & & & \\
\hline & OPE3 & 0.781 & & & \\
\hline \multirow{3}{*}{ Neuroticism (NEU) } & NEU1 & 0.820 & \multirow{3}{*}{0.801} & \multirow{3}{*}{0.813} & \multirow{3}{*}{0.592} \\
\hline & NEU2 & 0.757 & & & \\
\hline & NEU3 & 0.729 & & & \\
\hline \multirow{3}{*}{ Business performance } & BE1 & 0.863 & \multirow{3}{*}{0.724} & \multirow{3}{*}{0.845} & \multirow{3}{*}{0.645} \\
\hline & BE2 & 0.790 & & & \\
\hline & BE3 & 0.753 & & & \\
\hline
\end{tabular}

Table 5: Discriminant Validity

\begin{tabular}{|c|c|c|c|c|c|c|}
\hline Construct & $\mathbf{1}$ & $\mathbf{2}$ & $\mathbf{3}$ & $\mathbf{4}$ & $\mathbf{5}$ & $\mathbf{6}$ \\
\hline \hline BE & $\mathbf{0 . 8 0 3}$ & & & & & \\
\hline AGR & 0.466 & $\mathbf{0 . 8 2 6}$ & & & \\
\hline EXT & 0.616 & 0.508 & $\mathbf{0 . 8 0 1}$ & & \\
\hline CON & 0.611 & 0.601 & 0.533 & $\mathbf{0 . 8 2 2}$ & & \\
\hline OPE & 0.520 & 0.560 & 0.617 & 0.622 & $\mathbf{0 . 8 3 5}$ & \\
\hline NEU & -0.300 & -0.214 & -0.324 & -0.277 & -0.304 & $\mathbf{0 . 8 0 3}$ \\
\hline
\end{tabular}

Diagonals in bold signify the square root of the AVE while the other figures depict the correlations.

model fit. The results of the path coefficients and Tstatistics using the bootstrapping technique are depicted in Table 6.

Hypothesis one proposes that agreeableness is positively related to business performance. The results $(\beta=0.059, T=1.001, p>0.05)$ show an insignificant relationship between agreeableness and performance. Hypothesis one is rejected. Hypothesis two proposes that openness to experience is positively related to business performance. The results $(\beta=0.262, \mathrm{~T}=$ $3.714, p<0.05$ ) depict a significant positive relationship

Table 6: Path Coefficient and T-Statistics

\begin{tabular}{|c|c|c|c|}
\hline Hypothesised path & Standardised Beta & T-statistics & Decision \\
\hline \hline $\mathrm{H} 1 \mathrm{AGR} \rightarrow \mathrm{BP}$ & 0.059 & 1.001 & Rejected \\
\hline $\mathrm{H} 2 \mathrm{OPE} \rightarrow \mathrm{BP}$ & 0.262 & $3.714^{* *}$ & Accepted \\
\hline $\mathrm{H} 3 \mathrm{CON} \rightarrow \mathrm{BP}$ & 0.316 & $4.227^{*}$ & Accepted \\
\hline $\mathrm{H} 4 \mathrm{EXT} \rightarrow \mathrm{BP}$ & 0.277 & $3.850^{* *}$ & Accepted \\
\hline H5 NEU $\rightarrow \mathrm{BP}$ & -0.188 & $2.606^{* *}$ & Accepted \\
\hline
\end{tabular}

${ }^{*} p<0.01 ;{ }^{* *} p<0.05$. 
between openness and performance. Hypothesis two is accepted. Hypothesis three proposes that conscientiousness is positively related to business performance. The results $(\beta=0.316, T=4.227, p<0.01)$ show a significant relationship between conscientiousness and performance. Hypothesis three is accepted Hypothesis four proposes that there is a significant positive relationship extraversion and business performance. The results $(\beta=0.277, T=$ $3.850, \quad p<0.05)$ support a significant positive relationship between extraversion and performance. Hypothesis four is accepted. Hypothesis five proposes that neuroticism is negatively related to business performance. The results $(\beta=-0.158, T=2.606, p<0.05)$ show a significant negative relationship between neuroticism and performance. Hypothesis five is accepted.

\section{DISCUSSION}

The study investigated the relationship between personality traits using the Five-Factor model and the performance of immigrant-owned businesses in South Africa. The findings of the study indicated that agreeableness has an insignificant relationship with business performance. Agreeable entrepreneurs can be soft-hearted and tolerant and this may negatively affect the ability to take difficult decisions necessary to ensure business success. In addition, a high level of agreeableness may constrain the willingness of an entrepreneur to drive hard bargains, protect selfinterest and influence other people for one's own advantage (Zhao and Seibert, 2006). The results of this study are consistent with the findings of previous empirical studies. Hachana et al. (2018) and Mhlanga (2019) also find an insignificant relationship between agreeableness and entrepreneurial performance. The findings provided empirical evidence of a significant positive relationship between openness to experience and the performance of immigrant-owned businesses. Openness to experience can help an immigrant entrepreneur to be creative, innovative, alert to opportunities and adaptable to change leading to business success. Empirical studies (Shane, 2010; Wilfling \& Silbereisen, 2011). Hachana et al. (2013) and Mhlanga (2019) also find a significant positive relationship between openness to experience and business performance. The findings revealed a significant positive relationship between conscientiousness and business performance. Immigrant entrepreneurs with high levels of conscientiousness are organised, disciplined, risktakers and future-oriented. Previous empirical studies
(Zhao et al., 2010, Hachana et al., 2013, Mhlanga, 2019; Jawabri, 2019) find that conscientiousness has a significant positive association with entrepreneurial performance. The findings of the study indicated that extraversion has a significant positive relationship with business performance. Immigrant entrepreneurs with high levels of extraversion are sociable, outgoing and energetic and are able to develop solid networks which help to cultivate strong partnerships with customers, suppliers and providers of capital. Previous empirical studies by Zhao et al. (2010), Hachana et al. (2018) and Jawabri (2019) also find a significant positive relationship between extraversion and entrepreneurial performance. The findings of the study showed a significant negative relationship between neuroticism and business performance. The traits of entrepreneurs with high levels of neuroticism include anxiety, depression and hostility and vulnerability and this may negatively affect relationships with customers, suppliers and providers of capital. Empirical findings by Zhao et al. (2010), Hachana et al., (2018) and Mhlanga (2019) also find a significant negative relationship between neuroticism and entrepreneurial performance.

\section{CONCLUSION}

The study investigated the effect of personality traits on the performance of immigrant-owned small businesses using the Five factor theory. The findings indicated significant positive relationships between openness to experience, conscientiousness and extraversion and performance. The findings of the study provide insight into the nature of the relationship between personality traits and business performance in the context of immigrant-owned businesses. The study has some policy contributions. The findings this study can help individuals, businesses, government and nongovernmental organisations understand how to improve the performance of immigrant-owned businesses. Immigrant entrepreneurs should be proactive and attend training on the personality traits that can enhance their performance. Government and non-governmental agencies that support entrepreneurship in South Africa can use the findings of this study to recognise the personality traits of successful entrepreneurs. This can assist in the development of training programme for entrepreneurs. The study has some limitations. The study used the short fifteen-item measure of personality traits which although gives a good measure of the Big Five dimensions but does not permit the assessment of lower-order personality traits. Further studies can investigate if the longer and more detailed 


\section{Appendix 1: Questionnaire}

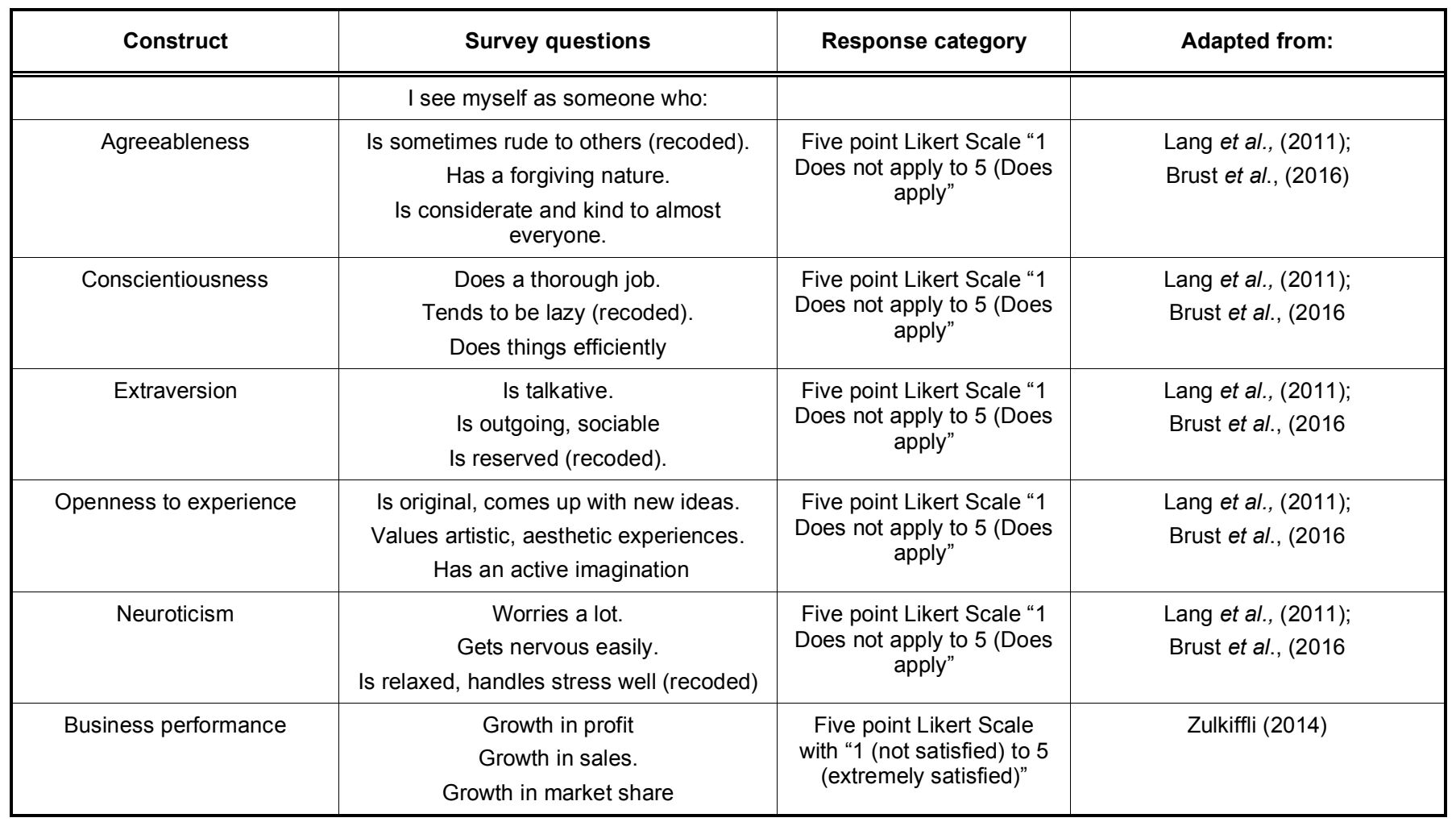

measurement of the Big Five factors will lead to a similar conclusion. The study used the self-report measure which often is limited by social desirability bias. This bias can be managed by the use of peer reports by other studies. Data was collected from only one hundred and ninety-six immigrant entrepreneurs and this limits the generalisability of the findings of this study. The moderating effect of demographic variables such as gender and age was not included in the study. Other studies should include moderating effects in order to improve the generalisability of the research findings to subgroups.

\section{REFERENCES}

Antoncic, Bostjan, Kregar, Tina, Singh, Gangaram, and DeNoble, Alex. 2015. "The Big Five Personality-Entrepreneurship Relationship: Evidence from Slovenia". Journal of Small Business Management 53(3): 819-841. https://doi.org/10.1111/jsbm.12089

Bajwa, Sami, Shahzad, Khuram and Aslam, Haris. 2017. "Exploring Big Five personality traits and gender as predictors of entrepreneurs' cognitive adaptability". Journal of Modelling in Management 12(1):143-161. https://doi.org/10.1108/JM2-04-2014-0026

Baluku, Martin Mabunda, Kikooma, Julius Fred, and Kibanja, Grace Milly. 2016. "Does Personality of Owners of Micro Enterprises Matter for the Relationship Between Startup Capital and Entrepreneurial Success?", African Journal of Business Management 10(1): 13-23. https://doi.org/10.5897/AJBM2015.7738
Bonacich, Edna. 1973. "A Theory of Middleman Minorities". American Sociological Review 38(5): 583-594. https://doi.org/10.2307/2094409

Brandstätter, Hermann. 2011. "Personality aspects of entrepreneurship: A look at five meta-analyses". Personality and Individual Differences 51(3):222-230. https://doi.org/10.1016/j.paid.2010.07.007

Brust, Oliver, Hader, Sabine, and Hader, Micheal. 2016. "Is the Short Version of the Big Five Inventory (BFI-S) Applicable for Use in Telephone Surveys?". Journal of Official Statistics 32(3): 601-618. https://doi.org/10.1515/jos-2016-0031

Cantner, Uwe, Silbereisen, Rainer, and Wilfling, Sebastian. 2011. "Which Big-Five Personality Traits Drive Entrepreneurial Failure in Highly Innovative Industries?", Proceedings of the DIME-DRUID Academy Winter Conference, Aalborg, Denmark.

Chin, Wynne 2010. "How to write up and report PLS analyses" Handbook of partial least squares. Springer. https://doi.org/10.1007/978-3-540-32827-8_29

Evans, Mdr. 1989. "Immigrant Entrepreneurship: Effects of Ethnic Market Size and Isolated Labor Pool". American Sociological Review 54(6): 950-962. https://doi.org/10.2307/2095717

Goldberg, Lewis. 1990. "An Alternative 'Description of Personality': The Big Five Factor Structure". Journal of Personality and Social Psychology $1,59,1216-1229$. https://doi.org/10.1037/0022-3514.59.6.1216

Government Gazette, 2019. Revised Schedule 1 of the National Definition of Small Enterprise in South Africa https://www.gov.za/sites/default/files/gcis_document/201903/ 423041gon399.pdf (accessed on 25 April 2019).

Hachana, Rym, Berraies, Sarra, and Ftiti, Zied. 2018. "Identifying personality traits associated with entrepreneurial success: 
does gender matter? Journal of Innovation Economics \& Management", 3(27):169-193.

https://doi.org/10.3917/jie.027.0169

Hair, Joseph, Risher Jeffrey, Sarsstedt, Marko, and Ringle Christain. 2019. "When to use and how to report the results of PLSSEM". European Business Review 31: 2-24.

https://doi.org/10.1108/EBR-11-2018-0203

Henseler, Jorg, Ringle, Christain, and Sarstedt, Marko. 2015. "A new criterion for assessing discriminant validity in variance-based structural equation modelling". Journal of the Academy of Marketing Science 43(1): 115-135. https://doi.org/10.1007/s11747-014-0403-8

Howard, Pierce and Howard, Jane. 1995. "The Big Five quickstart: an introduction to the Five-Factor Model of Personality for human resource professionals". Charlotte, NC: Centre for Applied Cognitive Studies.

Jawabri, Adnan. 2019. "The impact of big-5 model leadership traits on team entrepreneurship: An empirical study of small businesses in the UAE". Management Science Letters, 10, 497-506. https://doi.org/10.5267/j.msl.2019.9.031

Kalitanyi, Vivence, and Visser, Kobus. 2010. "African immigrants in South Africa: job takers or job creators?" South African Journal of Economic and Management Sciences 13(4): 376-390. https://doi.org/10.4102/sajems.v13i4.91

Masurel, Enno, Nijkamp, Peter, and Vindigni, Gabriella. 2004. Breeding places for ethnic entrepreneurs:a comparative marketing approach', Entrepreneurship \& Regional Development, 16: 77-86. https://doi.org/10.1080/0898562042000205045

Kerr, Sari, Kerr, William, and Xu, Tina. 2017. "Personality Traits of Entrepreneurs: A Review of Recent Literature". Foundations and Trends in Entrepreneurship 14(3):279-356. https://doi.org/10.1561/0300000080

Lang, Frieder, John, Dennis, Lüdtke, Oliver, Schupp, Jurgen, and Wagner, Gert. 2011. "Short assessment of the Big Five: robust across survey methods except telephone interviewing". Behavioural Research 43:548-567. https://doi.org/10.3758/s13428-011-0066-z

Leutner, Franziska, Ahmetoglu, Gorkan, Akhtar, Reece, and Chammoro-Premuzic, Thomas. 2014. "The relationship between the entrepreneurial personality and the big-five personality traits". Personality and Individual Differences 63:58-63.

https://doi.org/10.1016/j.paid.2014.01.042

Light, Ivan. 1979. "Disadvantaged Minorities in Self-Employment". International Journal of Comparative Sociology 20: 31-45. https://doi.org/10.1163/156854279X00157

McCrae, Robert, and Costa, Paul. 1985. "Updating Norman's "adequacy taxonomy": Intelligence and personality dimensions in natural language and in questionnaires". Journal of Personality and Social Psychology 49(3): 710-721. https://doi.org/10.1037/0022-3514.49.3.710

McCrae, Robert, and John, Oliver. 1992. "An introduction to the FFM and its applications". Journal of Personality 60: 175-215. https://doi.org/10.1111/j.1467-6494.1992.tb00970.x

Mhlanga, Oswald. 2019. "Identification of personality traits affecting entrepreneurial performance in the hospitality subsector: $A$ five-factor personality model". Acta Commercii, 19(2):1-9. https://doi.org/10.4102/ac.v19i2.651
Norman, Warren. 1967. "2800 personality trait descriptors: Normative operating characteristics for a university population". Ann Arbor: Department of Psychology, University of Michigan. ERIC Document Number xt/ED014738.

Omisakin, Olufemi Muibi. 2017. "Economic Contributions and Challenges of Immigrant Entrepreneurs to Their Host Country - Case of African Immigrants in Auckland, New Zealand". Journal of Business Administration Research 6(1): 25-38. https://doi.org/10.5430/jbar.v6n1p25

Omar, Khatijah, Anuar, Marhana, Ahmad, Azlinzurain, Zulkifli, Nur, and Hau, Tan. 2017. "Personality and business performance: A case of entrepreneurs". International Journal of Advanced and Applied Sciences 4(12):231-237. https://doi.org/10.21833/ijaas.2017.012.040

Osorio, Miguel, Urquiza, Alfonso, and Rodriguez, Rosana. 2015. "Value contribution of immigrants to society through entrepreneurship". Journal of Educators, Teachers and Trainers, 6(2): 101-112. http://www.ugr.es/ jett/index.php

Owens, Kimberly, Kirwan Jeral, Lounsbury John, Levy Jacob, and Gibson Lucy. 2013. "Personality Correlates of Self-Employed Small Business Owners' Success. Work". A Journal of Prevention, Assessment \& Rehabilitation, 45(1):73-85. https://doi.org/10.3233/WOR-121536

Shane, Scott, Nicolau, Nicos, Cherkas, Lynn, and Spector, Tim. 2010. "Genetics, the Big Five, and the Tendency to be SelfEmployed"'. The Journal of Applied Psychology 95(6): 11541162. https://doi.org/10.1037/a0020294

Small Business Institute, 2018. The number of formal micros, small \& medium businesses in South Africa. https://www.smallbusinessinstitute.co.za/wpcontent/uploads/2018/10/SBIbaselineAlert1 final.pdf.

Tella, Samson Afeverki. 2015. "Immigrant entrepreneurship: Towards the Realization of Immigrants' Entrepreneurial Performance and Success in Norway". Unpublished Masters thesis. NTNU-Trondheim. Norwegian University of Science and Technology.

Tengeh, Robertson, and Nkem, Linus. (2017). "Sustaining immigrant entrepreneurship in South Africa: The role of informal financial associations". Sustainability 9(8): 1396-1412. https://doi.org/10.3390/su9081396

Vinogradov, Evgueni, and Isaksen, Espen. 2008. "Survival of new firms owned by natives and immigrants in Norway". Journal of Developmental Entrepreneurship 13(1): 21-38. https://doi.org/10.1142/S1084946708000831

Waldinger, Roger, Aldrich, Howard. and Ward, Robin. 1990. Ethnic entrepreneurs. Newbury Park: Sage.

Zhao, Hao, and Seibert, Scott. 2006. The big five personality dimensions and entrepreneurial status: A meta-analytical review. Journal of Applied Psychology, 91(2): 259. https://doi.org/10.1037/0021-9010.91.2.259

Zhao, Hao, Seibert, Scott, and Lumpkin, GT. 2010. "The Relationship of Personality to Entrepreneurial Intentions and Performance: A Meta-Analytic Review". Journal of Management 36(2): 381404. https://doi.org/10.1177/0149206309335187

Zulkiffli, Siti. 2014. "Business Performance for SMEs: Subjective or Objective Measures?" Review of Integrative Business and Economics Research 3(1): 371-381. www.sibresearch.org.

\section{DOI: https://doi.org/10.6000/1929-7092.2020.09.31}

(c) 2020 Duc and Linh; Licensee Lifescience Global.

This is an open access article licensed under the terms of the Creative Commons Attribution Non-Commercial License (http://creativecommons.org/licenses/by-nc/3.0/) which permits unrestricted, non-commercial use, distribution and reproduction in any medium, provided the work is properly cited. 